high-frequency stimulator that blankets the re-entry zone, and thereby fortuitously induces a suitably timed extrasystole $;^{3}$ and the variable-hysteresis orthorhythmic pacemaker." These are all experimental, and implantable units are not available. Fixedrate pacing, however, is known to be of value in some cases, and this may be achieved either by using a demand pacemaker with a magnetic reed switch activated by an external magnet ${ }^{4}$ or by holding an external induction-coil ${ }^{5}$ or radio-frequency pacemaker $^{6}$ over the site of an implanted receiver. These latter methods, however, need the active intervention of the patient. If tachycardia is associated with syncope, or if serious attacks occur during sleep, the patient may be at considerable risk before the pacemaker can be activated. Here the dual-demand pacemaker may help. By automatically switching from the demand to the fixed-rate mode in response to the rate of the heart, units can be tailored to function at rates corresponding to the patient's tachycardia. Careful intracardiac electrophysiological studies ${ }^{12}$ will show whether the method is suitable for a particular patient. The unit can easily be tested at follow-up if competitive atrial pacing is induced by an external magnet applied over the generator, which will initiate an attack after a variable period. If the magnet is then removed the unit can be seen to function and terminate the attack.

Both of our patients had pre-excitation, and such units may well have their greatest application in this field. When the bypass is left-sided, stimulation from the coronary sinus ${ }^{13}$ offers the facility to influence both the nodal and extranodal limbs of the tachycardia circuit and may thus increase the chance of terminating re-entry. We have studied several other patients who were satisfactorily controlled by antiarrhythmic drugs in whom dual-demand pacemaking was tested successfully. For selected cases the dual-demand pacemaker offers an automatic unit that can be pretested and that works in response to the patient's own tachycardia, switching itself off after the tachycardia has been controlled unless bradycardia (perhaps due to sinoatrial disease) persists, when it acts to prevent both syncope and further recurrences.

This work was supported by a grant from the British Heart Foundation. We are grateful to Dr Philippe Coumel, who helped with the investigation of case 1 , for advice in the development of the pacemaker, and to Dr Celia Oakley, who kindly referred the patients.

\section{References}

1 Wellens, H J J, Electrical Stimulation of the Heart in the Study and Treatment of Arrhythmias, Leiden, Stenfert Kroese, 1971.

Guize, L, Zacouto, F, and Lenégre, J, Presse Médicale, 1971, 79, 2071.

${ }^{3}$ Spurrell, R A J, in Cardiac Arrhythmias, the Modern Electrophysiological Approach, ed. D M Krikler and J F Goodwin, p 238. London, Saunders, 1975.

${ }^{4}$ Ryan, G F, et al, Circulation, 1968, 38, 1037.

Dreifus, L S, et al, American fournal of Cardiology, 1971, 28, 586.

Williams, D O, and Davison, P H, British Heart fournal, 1974, 36, 336 Krikler, D, et al. Submitted for publication.

${ }^{-}$Krikler, D M, in Cardiac Arrhythmias, the Modern Electrophysiological Approach, ed D M Krikler and J F Goodwin, p 144. London, Saunders, 1975.

${ }^{9}$ Krikler, D M, and Spurrell, R A J, Postgraduate Medical fournal, 1974, 50, 447.

${ }^{10}$ Harper, R, et al, European fournal of Cardiology, 1974, 2, 207.

11 Coumel, $\mathrm{Ph}$, et al, British Heart fournal. In press.

12 Curry, P V L, in Cardiac Arrhythmias, the Modern Electrophysiological Approach, ed D M Krikler and J F Goodwin, p 39. London, Saunders, 1975.

${ }^{13}$ Kramer, D H, and Moss, A J, Circulation, 1970, 42, 427.

\title{
A controlled comparison of flupenthixol and amitriptyline in depressed outpatients
}

\author{
J P R YOUNG, W C HUGHES, M H LADER
}

British Medical fournal, 1976, 1, 1116-1118

\section{Summary}

Sixty depressed outpatients were allocated to treatment with either amitriptyline (75-225 $\mathrm{mg} /$ day) or flupenthixol $(1.5-4.5 \mathrm{mg} /$ day) in flexible dosage for six weeks under double-blind procedures. Various objective and subjective assessments were carried out before and after one, three, and six weeks of treatment. Twenty-three patients completed the course of amitriptyline and 28 the course of flupenthixol. Almost all variables improved significantly over time, irrespective of drug. On most ratings there were no significant differences between the two drugs, but the trends favoured flupenthixol. In particular, flupenthixol lessened anxiety scores more than amitriptyline. Unwanted effects were few and not trouble-

St Thomas's Hospital, London SE1

J P R YOUNG, MD, MRCP, consultant in psychological medicine W C HUGHES, MB, BS, senior registrar in psychological medicine

Institute of Psychiatry, University of London, London SE5 M H LADER, MD, PHD, reader in clinical psychopharmacology some except in two patients receiving amitriptyline. Flupenthixol, in low dosage, is a useful alternative antidepressant for depressed outpatients.

\section{Introduction}

The thioxanthene derivative flupenthixol is of established value in the treatment of schizophrenia. ${ }^{1}$ After some early reports, ${ }^{23}$ Reiter $^{4}$ described his uncontrolled impression of the antidepressant effect of flupenthixol in low doses in an extensive outpatient series. The recovery rate was over $60 \%$, and he claimed that flupenthixol was quick acting, effective in low doses, and without significant unwanted effects. Merskey ${ }^{5}$ noted a "worth-while sustained improvement" in 24 out of 53 patients with affective disorders. In 12 patients the depression was endogenous; in most the illness was chronic, and many patients had not responded to treatment with tricyclic compounds, monoamine oxidase inhibitors, or electric convulsion therapy (ECT). Others have noted flupenthixol's antidepressant properties, ${ }^{6-8}$ and Frolund ${ }^{9}$ found the drug effective in a trial with 231 patients suffering from anxiety and depression. Flupenthixol was given for only two weeks, however, and the drop out rate was high. Treatment was again given for only two weeks in a double-blind comparative trial which showed flupenthixol to be more effective than nortriptyline in the 
treatment of mild depression associated with anxiety or psychosomatic symptoms, or both. ${ }^{10}$

Unlike tricyclic antidepressants, flupenthixol has low toxicity, and, unlike the benzodiazepines, dependence is unknown. A controlled comparison of the drug against a standard tricyclic compound in outpatients with predominant symptoms of depression seemed appropriate.

\section{Methods}

Physically healthy adult outpatients, aged $20-70$, presenting with mild or moderately severe depression not requiring ECT were eligible for inclusion. All patients with schizophrenic or organic features or those who had been receiving antidepressant drugs or ECT during the three weeks before referral were excluded. Most patients were, however, taking sedatives or tranquillisers when first seen in the outpatient department. All patients had been newly referred, most by general practitioners and the remainder from within the hospital. Successive patients who were suitable for drug treatment were allocated randomly to either amitriptyline or flupenthixol treatment with the sole restraint that there should be 30 in each group.

Of the 60 patients initially entered in the trial nine were withdrawn, (seven in the amitriptyline group, two in the flupenthixol group). The amitriptyline group comprised 23 patients ( 15 women, 8 men) with a mean age of 39 years and a mean duration of the present episode of 25 months; seven patients had a family history of affective disorder, and 10 patients had had previous depressive episodes. In the flupenthixol group of 28 ( 15 women and 13 men) the mean age was 36 and the mean duration 18 months; seven patients had a family history of affective disorders and seven patients had had depressive episodes.

Both drugs were identically formulated, each tablet containing either $0.5 \mathrm{mg}$ flupenthixol or $25 \mathrm{mg}$ amitriptyline. The dose was regulated, using flexible schedules, to three to nine tablets daily, depending on the patient's response. The mean daily dose of both drugs was five tablets (amitriptyline $125 \mathrm{mg}$; flupenthixol $2.5 \mathrm{mg}$ ). The trial was carried out double-blind. No additional medication was prescribed apart from diazepam and nitrazepam in low doses when absolutely necessary as day-time and night-time sedatives respectively. In the amitriptyline group diazepam was prescribed for 11 patients (mean dose $11 \mathrm{mg}$ daily) and nitrazepam for six patients (mean $7 \mathrm{mg}$ /day); in the flupenthixol group diazepam was given to 14 patients (mean $9 \mathrm{mg} /$ day) and nitrazepam to $\operatorname{six}$ (mean $8 \mathrm{mg} /$ day). There were thus no great differences between the groups. The treatments were continued for six weeks, each patient being seen for initial assessment and th:n after one, three, and six weeks of treatment.

Assessment ratings were made at each visit. The patient completed the Beck scale for depression and the Middlesex Hospital Questionnaire (MHQ), and an independent assessor scored the patient on the Hamilton rating scale for depression and the MRC depression scale and made an overall rating of the severity of depression. A standard form for rating side effects was completed by the psychiatrist who regulated drug dosage to prevent knowledge of side effects biasing the clinical ratings of the other assessor.

\section{Results}

Reasons for withdrawal-Of the original 30 patients allocated to the amitriptyline group, three were withdrawn because their condition deteriorated, two because they developed intolerable unwanted effects (drowsiness and tremor), and two for reasons unconnected with the trial. One patient allocated to the flupenthixol group was withdrawn because her depression got worse and one for reasons unconnected with the treatment.

Pretreatment matching of groups-Although the patients had been allocated randomly to the two treatment groups, differences between the two groups might have arisen by chance. But $\chi^{2}$ tests and $t$ tests showed no unusually large chance differences (at the 0.05 level) between the groups with respect to sex, age, duration of present episode, ratings on Hamilton scale and Beck scale, MHQ scores, MRC scale items, and total score of overall severity rating.

Change with treatment-Analyses of variance including trend analyses were carried out on the pretreatment scores and the three treatment scores. All clinical variables improved significantly over time except for the MHQ phobia, hysteria, and obsessions scales. In almost all the variables the linear trend was highly significant, suggesting a steady improvement. For most variables there were no significant differences between the two treatments. Thus for scores on the Hamilton and Beck scales, MRC total score, and rating of overall severity, similar improvements were found (see fig). Anxiety (MRC scale), however, was ameliorated significantly more by flupenthixol $(\mathrm{P}<0.05)$, whereas insomnia (MRC scale) was slightly more apparent with this drug (see fig). Somatic symptoms (MRC scale) and the side effect of tremor were definitely more troublesome in the amitriptyline group $(\mathrm{P}<0.01$ and $\mathrm{P}<0.05$ respectively). Generally, the trends consistently favoured flupenthixol with respect to both the adequacy of the antidepressant and antianxiety effects and the paucity of unwanted effects.
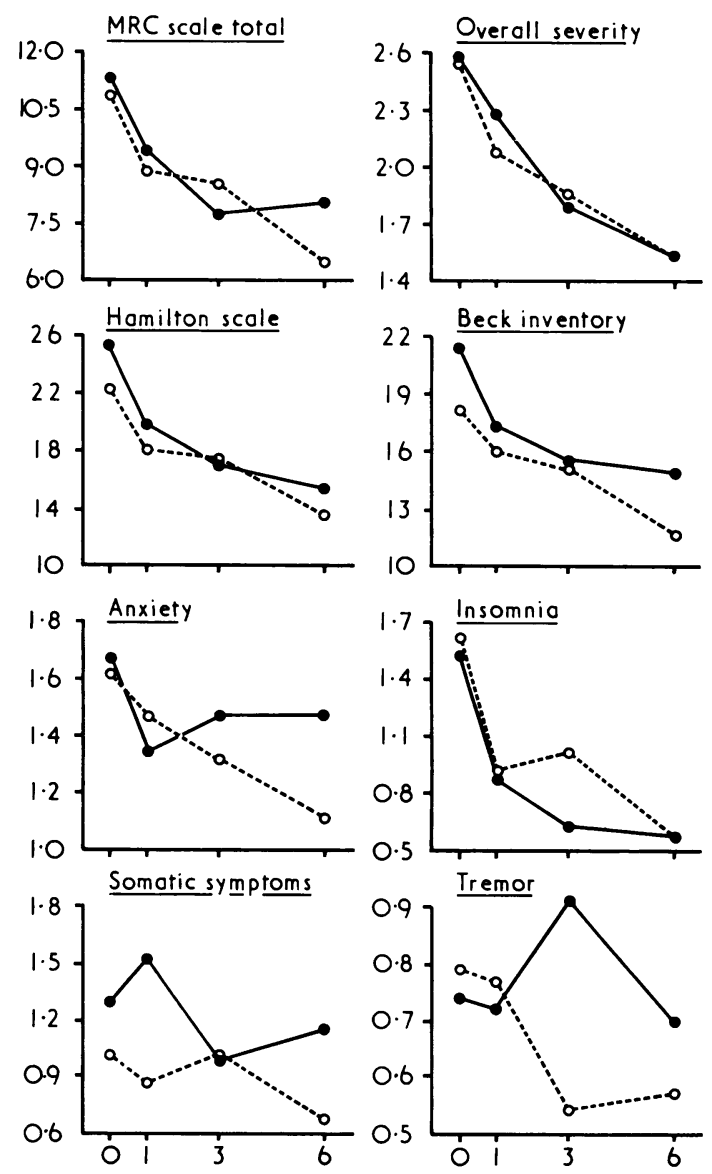

Mean values for various ratings for groups of patients treated with amitriptyline (-O) or flupenthixol ( $\left.\mathrm{O}_{-} \mathrm{O}_{-} \mathrm{O}\right)$ for six weeks.

Relation of outcome to pretreatment scores-There were no consistently strong relations between pretreatment severity and outcome or between the clinical features of the patient and outcome. There was also no evidence of differential response in the two groups. Thus no prediction of treatment outcome was possible.

Treatment at end of trial-At the end of the six-week trial the patient was placed on whatever treatment the consultant in charge deemed appropriate. Of the 23 patients in the amitriptyline group 19 continued with antidepressants (tricyclic drugs or monoamine oxidase inhibitors, or both) and four were judged "cured" and did not require psychotropic drugs. Eighteen of the 28 patients on flupenthixol were given antidepressants, three were given only diazepam, and seven received no further drug treatment. Thus there was a non-significant trend in favour of flupenthixol.

\section{Discussion}

The results clearly indicate that flupenthixol effectively relieves mild or moderate symptoms of depression with associated anxiety. In the patients studied the drug proved at least as effective as amitriptyline as both an antidepressant and an anxiolytic and it was less likely to produce side effects. There was no difference between the drugs in speed of onset of action. 
Though not severely depressed, the patients studied seemed typical of those referred to hospital for antidepressant outpatient treatment, their mean Hamilton depression score being 24 .

These findings are similar to the results of several mainly uncontrolled studies. Nistico et $a l^{11}$ reported the development of hypomania during treatment with flupenthixol in four out of 32 patients, which by itself strongly suggests that the drug has antidepressant properties. The improvement recorded during our trial, however, may have been due partly to anxiolytic drug effects. This might apply to both flupenthixol and amitriptyline, as it seems to apply to other antidepressants that are effective against primary anxiety and phobic states ${ }^{12}$ and to other major tranquillisers, such as thioridazine, effective against some forms of depression..$^{13}$ In fact, the precise nosological relations between anxiety and depression remain not clear.

Within the limits of our present findings, flupenthixol is a useful alternative antidepressant, which acts rapidly, is effective in low doses, and has no serious side effects. With increased dosage the drug has acknowledged antipsychotic properties, and recorded side effects include extrapyramidal features and insomnia. There is no tendency towards dependence, as there is with the benzodiazepines, and toxicity after an overdose is much lower with flupenthixol than with tricyclic drugs.

Several treatment possibilities suggest themselves. Since many outpatients are unreliable in taking oral medication, ${ }^{14}$ the effects of flupenthixol given parenterally in depot form to depressed patients would be interesting. The risk of overdose would be reduced and adequate blood levels presumably maintained. The effectiveness of long-acting intramuscularly administered flupenthixol might also be tested as a prophylactic against frequently recurrent depressive illness. Nevertheless, the possibility of untoward reactions such as persistent dyskinesias cannot be ignored. There are clear structural and pharmacological differences between the thioxanthenes and tricyclic antidepressants, and the mode of clinical action of the two groups of drugs may also differ. Possibly, therefore, the antidepressant effects of combined treatment with flupenthixol and a tricyclic drug may be additive.

We are grateful to $\mathrm{H}$ Lundbeck and Co for providing the drugs used in this trial and to Jan Müller and Gerald Samuel for many helpful discussions.

\section{References}

1 Gottfries, C G, British fournal of Psychiatry, 1971, 119, 547.

${ }^{2}$ Holst, B, Nordisk Psykiatrisk Tidsskrift, 1965, 1965, 19, 59.

${ }^{3}$ Sonne, L M, Nordisk Psykiatrisk Tidsskrift, 1966, 20, 322.

${ }^{4}$ Reiter, P J, British Fournal of Psychiatry, 1969, 115, 1399.

${ }^{5}$ Merskey, H, British fournal of Psychiatry, 1971, 119, 230.

6 Van Coller, P E, Psychosomatics, 1971, 32, 256.

7 Predescu, V, et al, Acta Psychiatrica Scandinavica, 1973, 49, 15

${ }^{8}$ Sonne, L M, Nordisk Psykiatrisk Tidsskrift, 1971, 25, 454.

${ }^{9}$ Frolund, F, Current Medical Research and Opinion, 1974, 2, 78.

${ }^{10}$ Rosenberg, I U, Ostensen, A I, and Fonnel $\phi \mathrm{p}, \mathrm{H}$, Tidsskrift for den Norske Laegeforening, 1976, 96, 229.

11 Nistico, G, Marano, V, and Scapagnini, U, Acta Neurologica Napoli, 1975, 30, 102.

12 Tyrer, P, Candy, J, and Kelly, D, Psychological Medicine, 1973, 3, 120.

13 Overall, J E, et al, fournal of the American Medical Association, 1964, 189, 605.

${ }^{14}$ Hare, E H, and Willcox, D R C, British fournal of Psychiatry, 1967, 113, 1435 .

\title{
Value of gallium scanning in seminoma of the testis
}

\author{
A H G PATERSON， M J PECKHAM， V R MCCREADY
}

British Medical fournal, 1976, 1, 1118-1121

\begin{abstract}
Summary
Whole-body scanning using gallium-67-citrate gave consistently accurate tumour localisation in patients with seminoma of the testis. Thirteen out of 15 scans performed in patients with disseminated seminoma in relapse gave good imaging in all disease areas. Scans in patients with teratoma of the testis were less consistently positive; of nine scans performed in patients with disseminated teratoma seven were entirely negative and two scans lightly imaged large disease masses in two patients. In eight patients with combined (seminoma and teratoma) tumours the scan seemed to reflect the dominant tumour type at the time of scanning. In one of these patients the scans changed from positive to negative, being positive
\end{abstract}

\footnotetext{
Department of Nuclear Medicine, Royal Marsden Hospital and Institute of Cancer Research, Sutton, Surrey

A H G PATERSON, MB, MRCP, research fellow

V R MCCREADY, MRCP, FRCR, consultant in nuclear medicine

Department of Radiotherapy, Royal Marsden Hospital and Institut of Cancer Research, Sutton, Surrey

M J PECKHAM, MD, FRCR, professor of radiotherapy
}

when seminoma was the dominant tumour and negative when a teratoma developed.

Gallium-67-citrate scanning is useful in managing seminoma of the testis, both for determining the extent of disease present at initial presentation and for routine follow-up. It may be useful in the differential diagnosis of combined tumours when tumour masses are greater than $2 \mathrm{~cm}$ in diameter.

\section{Introduction}

A satisfactory tumour localising agent for the testicular tumours would help in deciding on treatment, localising the tumour for external radiation, and monitoring the response of the disease to treatment.

In seminomas disease localisation is important since this tumour is exceedingly sensitive to radiation, and sites that are usually vulnerable to radiation damage, such as the liver and lungs, can be irradiated to tumouricidal dose levels without prohibitive normal tissue damage. Thus, widespread disease is not necessarily incompatible with cure. In testicular teratomas there is the added problem of staging, which is particularly relevant to a combined irradiation-chemotherapy approach for disease that has spread to the lungs and when it is important to exclude liver disease.

From 1972 we have assessed the tumour imaging agent ${ }^{67} \mathrm{Ga}$-citrate in the whole-body scanning of patients with testicular tumours. ${ }^{67} \mathrm{Ga}$-citrate is prominent among tumour 